\title{
Quem são os direitos humanos? Desconsideração e personificação em cadeias do Distrito Federal
}

\author{
Who are human rights? Disrespect and personification \\ in prisons of the Federal District, Brazil
}

\section{Carolina Barreto Lemos}

Brasil. Universidade de Brasília. Pesquisadora formada em Direito pela Universidade Federal de Minas Gerais (UFMG). Em 2010, obteve seu mestrado em Filosofia na Université Paris 1 Panthéon-Sorbonne. No ano de 2017, concluiu sua tese de doutorado na Faculdade de Direito da Universidade de Brasília (UnB). Atualmente, é professora colaboradora do Programa de Pós-Graduação em Antropologia Social da UnB. Além disso, épesquisadora vinculada ao Instituto de Estudos Comparados de Administração Institucional de Conflitos da Universidade Federal Fluminense (INCT-InEAC/UFF). ID ORCID: https://orcid.org/0000-0002-2571-4961.E-mail:cbarretolemos@gmail.com.

\section{Resumo}

Este texto analisa as concepções de direitos humanos formuladas por mulheres e homens presos que puxam pena no Distrito Federal. Argumento que essas concepções só podem ser adequadamente compreendidas se analisarmos sua articulação com o modo como as categorias direitos e humanos são acionados nesse contexto. Isso porque, como pretendo demonstrar, os sentidos das três categorias se associam a experiências de desconsideração que sinalizam a denegação ou privação de reconhecimento social nessas instituições prisionais. Por fim, partindo da análise desse campo etnográfico, gostaria de propor que os direitos humanos, concebidos não como entidades universais e abstratas, mas como determinada prática que se situa no plano concreto das relações intersubjetivas, podem funcionar como um importante vetor de reconhecimento e de concretização de direitos no contexto da privação de liberdade no Brasil.

Palavras-chave: Direitos Humanos, Desconsideração, Personificação, Reconhecimento, Encarceramento. 


\section{Abstract}

This paper analyzes conceptions of human rights among women and men incarcerated in the Federal District, Brazil. I argue that such conceptions can only be properly understood by analyzing their relation to how the "rights" and "humans" categories are triggered in prison environments. The meanings of these three concepts - rights, humans and human rights - are associated with experiences of disrespect that reveal the denial of social recognition within prison walls. Finally, I propose that human rights, conceived not as universal and abstract entities, but as a kind of practice - situated in the realm of concrete intersubjective relationships - may function as an important instrument to recreate the conditions for social recognition and implementation of rights in the context of Brazilian prisons.

Keywords: Human Rights, Disrespect, Personification, Recognition, Incarceration.

Este texto analisa a concepção de direitos humanos ${ }^{1}$ formuladas por mulheres e homens que puxam pena ${ }^{2}$ no Distrito Federal. Argumento que essa concepção só pode ser adequadamente compreendida se analisarmos sua articulação com o modo como as categorias direitos e humanos são acionados nesse contexto. Isso porque, como pretendo demonstrar, os sentidos das três categorias se associam a experiências de desconsideração que sinalizam a denegação ou privação de reconhecimento social nessas instituições prisionais. Por fim, partindo da análise desse campo etnográfico, gostaria de propor que os direitos humanos, concebidos não como entidades universais e abstratas, mas como agentes de determinada prática que se situa no plano concreto das relações intersubjetivas, podem representar um importante vetor de reconhecimento social e de concretização de direitos no contexto da privação de liberdade no Brasil.

Tomo, aqui, direitos humanos como um conceito que não tem sentido único, mas como uma categoria que encontra diferentes significados e modos

\footnotetext{
Ao longo deste texto, o uso de itálico indicará uma fala ou categoria nativa.

2 Categoria que designa não apenas a ideia de cumprir pena, mas abarca igualmente os sentidos simbólicos que essa experiência assume para pessoas privadas de liberdade.
} 
de acionamento em contextos distintos. Compreendo, desse modo, direitos humanos como um conceito polissêmico que éhistórica e geograficamente situado, se desenvolvendo de modo não linear e sendo interpretado de modos distintos. Neste texto, portanto, demonstrarei de que modo as concepções de direitos humanos acionadas pelos interlocutores nas cadeias do DF se articulam com a sensibilidade jurídica local e se distanciam de suas concepções legais ou jurídicas.

Os dados apresentados são o resultado de uma pesquisa de campo, realizada entre os anos 2014 e 2016 e 2017 e 2018, com mulheres e homens que cumpriam pena em cadeias do Distrito Federal (DF). O trabalho de campo teve caráter multifacetado devido às diversas dificuldades de acesso ao campo. Realizei, em um primeiro momento, 29 entrevistas com 12 mulheres e 10 homens em privação de liberdade no Distrito Federal. As entrevistas foram profundas, com duração entre 60 e 120 minutos, e não estruturadas, não seguindo um roteiro predefinido. Todas foram realizadas com privacidade e registradas com gravador de som. Das entrevistas, oito foram realizadas com mulheres que puxavam pena no regime fechado na Colmeia. As restantes foram realizadas com mulheres e homens que cumpriam pena no regime semiaberto ou aberto, ou que estavam em liberdade condicional, que trabalhavam ${ }^{3}$ em órgãos vinculados ao Ministério da Justiça. Depois da fase das entrevistas, motivada por diferentes circunstâncias, atuei - entre os anos 2015 e 2017 - como advogada nas cadeias locais, o que permitiu uma perspectiva singular sobre o campo e o acesso mais regular às unidades prisionais ${ }^{4}$.

\section{QUEM SÃO OS DIREITOS HUMANOS?}

A primeira vez em que me chamou atenção a singularidade da concepção de direitos humanos no contexto das cadeias locais foi durante uma conversa com Cleonice ${ }^{5}$ na Colmeia ${ }^{6}$. Cleonice puxava pena em regime fechado na unida-

\footnotetext{
3 Essas pessoas eram alocadas nesses órgãos por meio de um convênio com a Fundação de Amparo ao Trabalhador Preso (Funap) do DF.

4 Descrevi e analisei em profundidade este trabalho de campo em Lemos (2017).

5 Os nomes atribuídos aos/às interlocutores/as neste artigo são fictícios.

6 Penitenciária Feminina do Distrito Federal.
} 
de prisional feminina da Capital. Em uma das nossas conversas, contava-me que não era incomum as presas serem fisicamente agredidas na cadeia por agentes mulheres ou mesmo homens. Narra que, em determinada ocasião, logo depois de ter sido presa - quando, segundo ela, ainda estava muito revoltada e dava muito trabalho na cadeia - "tomou uma peia" (surra) de dois agentes masculinos. Ao dizer que achava errado esse tipo de conduta pelos agentes, Cleonice passou a falar sobre a atuação dos direitos humanos nesse contexto:

"Chamaram o agente masculino, aí me deu uma peia, menina, quase morri. Eles batem, como se tivessem batendo num homem. Aí quem não tem visita, né, eles batem e passa por isso mesmo. [...] Mas eu acho errado, por que que... igual, os direitos humanos passa, eles faz mil perguntas, né? A gente não pode nem falar, porque, se a gente falar a verdade, a gente vai pro isolamento" (Cleonice).

Perguntei, então, a Cleonice: “Quem são os direitos humanos?”, ao que ela respondeu:

"São pessoas que são a favor dos presos e das presas, que quer saber como é que tá o preso dentro de cela, quantas pessoas têm dentro da cela, igual, assim, suas perguntas, meio parecida... E tipo defende a gente, se a gente tá sendo maltratado. Só que a gente não fala a verdade, né, porque... igual uma vez eu gritei: 'a comida aqui tá vindo é azeda', peguei e fui pro isolamento. Só foi os direitos humanos virar as costas, fui pro isolamento. Por isso que eu nunca mais falei nada" (Cleonice).

O diálogo com Cleonice é ilustrativo do modo como os direitos humanos são frequentemente concebidos nas cadeias locais. Como ela, diversos/as interlocutores/as se referiam aos direitos humanos não como um conjunto de direitos universais abstratos dos quais, na condição de seres humanos, seriam titulares, mas como sujeitos, como pessoas que são a favor dos presos e das presas e que os/as defendem contra maus tratos, realizando visitas esporádicas às unidades prisionais. A personificação tem valor simbólico importante; no lugar de universalismo e transcendência, os direitos humanos visitam o presídio e, depois, viram as costas e partem. 
Relatos semelhantes aos de Cleonice ao longo da pesquisa de campo corroboram essa formulação de direitos humanos. Por exemplo, Leonardo, que puxava pena no regime semiaberto, se referindo ao período de cinco anos em que esteve preso no Cascavel $^{7}$, falou-me sobre as visitas dos direitos humanos. Contou que era comum, antes de os direitos humanos chegarem para fazer a visita, os agentes penitenciários ordenarem aos homens que ali estavam presos que fizessem uma boa limpeza nas alas e que desocupassem as celas, dirigindo-se ao pátio de banho de sol. Do seu ponto de vista, essa estratégia teria o objetivo de impedir que os direitos humanos verificassem, de modo adequado, as condições de superlotação e insalubridade das celas.

Mas a referência aos direitos humanos não se restringe aos momentos em que estes realizavam visitas ou inspeções nas cadeias. Nesse sentido, Francisco, que cumpria pena no regime semiaberto, conta que, quando estava preso no Centro de Detenção Provisória (CDP), fora atingido na barriga por um estilhaço de bomba de efeito moral na ocasião de uma invasão $0^{8}$ nas celas. Conta que a polícia ${ }^{9}$ queria mandá-lo para o castigo para evitar que a família visse a lesão e fizesse uma denúncia aos direitos humanos. Ele ressaltou que esse era um procedimento comum quando alguém era ferido durante essas operações dentro do presídio: colocar a pessoa no isolamento, período durante o qual não recebe visita dos familiares, impossibilitando que estes vejam as marcas das feridas, caso em que poderiam acionar os direitos humanos.

Chama atenção o modo como essa formulação de direitos humanos se distancia daquela encontrada em textos legais ou do campo jurídico. Para Cruft, Liao e Renzo (2015), os fundamentos teóricos dessa concepção de direitos humanos remontam à teoria dos direitos naturais, formulada por diferentes autores ao longo do século XVII em obras como O direito da guerra e da paz (1625), de Hugo Grotius, e Dois tratados sobre o governo (1689), de John Locke. Destacam, ainda, a importância das reflexões de Hobbes sobre o direito

\footnotetext{
7 Penitenciária do Distrito Federal.

8 Operações realizadas pela polícia (ver nota 9) nas celas ou pátio de banho de sol.

9 Polícia designa os/as agentes de segurança pública nas cadeias locais, o que inclui agentes da polícia civil, os/as agentes de atividades penitenciárias e da Diretoria Penitenciária de Operações Especiais (DPOE).
} 
natural em Leviatã (1651) e Do cidadão (1651), a partir das quais se passa a conceber os direitos como propriedades (atributos) da "natureza humana". É importante pontuar o papel fundamental das reflexões desse autor no contexto da formulação mesmo da noção de "direitos", no plural, e de sua distinção no plano conceitual da noção de "o direito", no singular ${ }^{10}$.

Essa distinção conceitual e a formulação dos direitos enquanto atributos da natureza humana formam os pressupostos fundamentais da concepção jurídico-legal de direitos humanos que hoje encontramos nos principais instrumentos legais internacionais. Ainda que tributária dessa tradição filosófica, surgida pelo menos três séculos antes, a expressão "direitos humanos" só surge e é positivada no século $\mathrm{XX}^{11}$, em instrumentos internacionais como a Declaração Universal dos Direitos Humanos (1948) e o Pacto de São José da Costa Rica (CONVENÇÃO AMERICANA DE DIREITOS HUMANOS,1969).

Segundo a Organização das Nações Unidas ([201-?], não paginado):

Os direitos humanos são direitos inerentes a todos os seres humanos, independentemente de raça, sexo, nacionalidade, etnia, idioma, religião ou qualquer outra condição. [...] Todos merecem estes direitos, sem discriminação.

Formulação semelhante pode ser encontrada no preâmbulo da Convenção Americana de Direitos Humanos (1969, não paginado):

Reconhecendo que os direitos essenciais da pessoa humana não derivam do fato de ser ela nacional de determinado Estado, mas sim do fato de ter como fundamento os atributos da pessoa humana [...].

O primeiro aspecto que chama atenção nessa concepção é o fato de os direitos serem formulados como objetos dos quais todos os seres humanos

${ }_{10}$ É mais fácil perceber essa distinção na língua inglesa, em que as palavras direitos (rights) e direito (law) têm etimologias distintas.

${ }^{11}$ A ideia de direitos universais, mesmo que não fossem ainda nomeados direitos humanos, já havia sido positivada nas grandes declarações do fim do século XVIII, no contexto dos movimentos revolucionários liberais-burgueses europeus e norte-americanos. 
seriam titulares. A relação entre o sujeito e os direitos é aqui representada como uma relação de propriedade, uma relação entre sujeito e objeto. Outro traço distintivo dessa formulação de direitos humanos é sua natureza transcendental: não são histórica, geográfica e politicamente situados; têm como fundamento os "atributos da pessoa humana". Os direitos humanos são aqui concebidos, portanto, como entidades abstratas, oponíveis a todos/as, que existem no plano das ideias, e não no das relações mundanas. Por fim, chama atenção a ideia de humanidade que permeia essa formulação. Ao conceber os direitos humanos como inerentes a todos os seres humanos, simplesmente em virtude de serem humanos, compreende-se a humanidade como categoria natural, intrínseca a todos/as aqueles que são da espécie humana.

A personificação dos direitos humanos pelos/as interlocutores/as como sujeitos se distancia, desse modo, da sua formulação jurídico-legal. Para compreender melhor esse fenômeno, gostaria de analisar em seguida como as duas categorias que informam essa concepção - direitos e humanos - são acionadas por essas mulheres e homens. Não pretendo, com isso, dizer que a categoria direitos humanos representa a justaposição (ou a soma) das noções direitos e humanos. Da mesma forma, aquela não abarca todos os sentidos destas. Entretanto as três categorias estão inseridas nas mesmas teias de significados e, desse modo, informam-se umas às outras. Por isso a análise do modo como os sentidos dessas três categorias se articulam é uma importante ferramenta para compreender mais profundamente a personificação dos direitos humanos nesses locais. Argumento, assim, que os modos de acionamento das três categorias se associam a experiências de desconsideração que sinalizam a denegação ou privação de reconhecimento social nesse contexto.

\section{DESCONSIDERAÇÃO E PERSONIFICAÇÃO}

Diferentes autores (CARDOSO, 2013, 2014; HONNETH, 2003; OLIVEIRA, 2011) destacaram a importância de se manter atento aos sentidos simbólicos das percepções de atores sociais em contextos de vulnerabilidade 
social, marcados principalmente pela pobreza e dificuldade de acesso a direitos. Isso porque, frequentemente, os protestos sociais formulados por esses grupos não são positivados em demandas traduzíveis para a linguagem jurídica formal, mas expressas por meio de relatos de experiências em que suas "noções intuitivas [ou nativas] de justiça” são violadas (HONNETH, 2003, p. 71). Para Oliveira (2011), a impossibilidade de articular essas experiências de injustiça nos termos do idioma jurídico-legal revela uma importante diferença entre a dimensão moral e legal da cidadania (ou do direito). Enquanto esta última estaria atrelada ao desrespeito a direitos positivados, a primeira seria marcada por noções de justiça calcadas em expectativas de consideração à pessoa.

Honneth (2003) destaca que o cerne dessas experiências de injustiça moral está associado à ideia de que uma parte importante da nossa identidade é construída por meio do reconhecimento social, ou seja, o reconhecimento recíproco das pessoas como entes morais - pessoas dignas - que merecem ser respeitadas (OLIVEIRA, 2011). Desse modo, a experiência da desconsideração, ou desrespeito, é identificada como a falta de reconhecimento social, o que pode afetar uma ou mais dimensões da identidade da pessoa, caracterizando uma importante forma de negação da dignidade no plano da cidadania (HONNETH, 2003; OLIVEIRA, 2011).

Honneth (1992) diferencia entre três formas de desconsideração - ou desrespeito - que podem perturbar a integridade pessoal, que só pode ser adquirida de maneira intersubjetiva. Aponta, primeiramente, as agressões à integridade física como a mais grave e destrutiva forma de desconsideração, pois perturba a relação fundamental entre o sujeito e seu corpo, interrompendo o processo de construção de uma imagem positiva do sujeito sobre si no plano corpóreo. A segunda forma de desconsideração apontada pelo autor surge em contextos de exclusão social e negação de direitos e se caracteriza pelo não reconhecimento de pessoas como sujeitos portadores de direitos, reconhecimento fundamental em qualquer relação de direito, seja no âmbito do Estado ou da sociedade civil. Por fim, a degradação e a ofensa (ou insulto), que rebaixam a estima e o valor social de grupos ou indivíduos, configurariam uma terceira forma de desconsideração, pois perturbam o senso de autorrealização 
necessário para forjar uma compreensão positiva de si mesmo ou de seu grupo social. Como veremos, no contexto das cadeias locais, mulheres e homens são recorrentemente submetidos a essas três formas de desconsideração, configurando o que nomeio como uma experiência radical de desconsideração.

Para identificar adequadamente essas experiências de desconsideração, é preciso dar especial atenção aos sentimentos "enquanto expressão de percepções ou representações socialmente compartilhadas, conectadas com as intuições morais dos atores" (OLIVEIRA, 2011, p. 21). Isso porque, em contextos em que diferentes dimensões do reconhecimento são ameaçadas, a ofensa moral causada por essas experiências não pode ser traduzida em termos estritamente legais.

Analisarei em seguida as categorias direitos, humanos e direitos humanos nas cadeias do DF, demonstrando como seus modos de acionamento se articulam com experiências de desconsideração nesse contexto.

\section{Direitos e regalias}

É interessante notar como a personificação dos direitos humanos nas cadeias do DF se articula com o esvaziamento do conteúdo material dos direitos formais de pessoas presas e com a ausência de critérios compartilhados para orientar a distribuição de direitos e regalias nesses espaços. Discuto a seguir de que modo, na prática cotidiana das cadeias, esse esvaziamento se torna possível por meio do não reconhecimento de presos/as como sujeitos de direitos, o que pode ser evidenciado pelos sentidos revelados pelas formas de acionamento das categorias direitos e regalias.

A esse respeito, o caso de Helena é especialmente ilustrativo. Meu primeiro contato com ela foi em 2014, no Departamento Penitenciário Nacional, onde era contratada por meio de um convênio com a Fundação de Aparo ao Trabalhador Preso (Funap), quando cumpria pena no regime aberto. Em meados de 2015, Helena foi novamente presa e processada criminalmente. Depois de sua segunda prisão, busquei reestabelecer contato com ela, primeiramente por meio de carta e, depois, lançando mão da minha habilitação profissional, e consegui visitá-la no presídio, ainda que, naquele momento, 
não fosse formalmente sua representante legal. Quando Helena recebeu sua sentença condenatória em primeira instância, ela me pediu que assumisse seu caso para entrar com recurso de apelação e tentar reverter sua condenação. Em meados de 2016, mais de um ano depois de sua prisão, Helena foi absolvida em segunda instância.

Durante esse tempo, enquanto nos preparávamos para a apelação, visitava Helena regularmente na prisão, onde cumpria antecipadamente sua pena em regime inicialmente fechado. Como a maioria das mulheres que puxam pena no regime fechado ali, Helena estava alocada na Ala C da Colmeia ${ }^{12}$. A despeito de essa ser oficialmente a norma, na prática, algumas mulheres que cumpriam pena no regime fechado - que trabalhavam e eram consideradas de bom comportamento ${ }^{13}$ - eram alocadas na Ala E daquela unidade, onde moram mulheres que puxam no regime semiaberto. Diferentemente da Ala C, a Ala E era dividida em quartos, e não celas, tinha jega (cama) para todas as habitantes, de modo que ninguém precisava dormir no chão, e era equipada com um espaço de convivência comum e banheiro com vasos sanitários ${ }^{14}$. Sendo um local com condições melhores de acomodação, Helena demandava o direito de ser alocada na Ala $\mathrm{E}$, já que trabalhava e era, do seu ponto de vista, uma interna de bom comportamento.

Chama atenção o fato de ela formular sua demanda - a troca de ala - como direito ainda que correspondesse a um sistema de benefícios - a realocação de mulheres que cumpriam pena no regime de fechado na ala do semiaberto - posto em prática na cadeia sem fundamento legal ou mesmo formal. Se, por um lado, Helena formulava sua demanda em termos de direito, porque acreditava fazer jus àquela vantagem, por outro, tanto ela quanto outras/os interlocutoras/es frequentemente recorriam à categoria regalia para se referir a direitos previstos formalmente na LEP, como o acesso a trabalho remunerado (Art. 41, II), à assistência escolar (Art. 41, VII) e o direito de receber visitas

\footnotetext{
${ }_{12}$ Presídio Feminino do Distrito Federal.

${ }_{13}$ Categoria polissêmica que traduz avaliações morais acerca do comportamento de mulheres e homens em instituições de privação de liberdade.

${ }^{14}$ Diferente da Ala C, em que o banheiro é uma vala no chão, sem assento ou descarga, no fundo da cela.
} 
(Art. 41, X). Confusa quanto à delimitação de cada categoria, um dia perguntei a Helena a diferença entre elas: "Regalia é tudo que beneficia as presas. [...] Mesmo o que é direito. É tipo esse negócio de eu mudar de ala".

As expressões "direitos" e "regalias" também aparecem na Lei de Execução Penal (BRASIL, 1984, Arts. 41, 55 e 56). Uma leitura do texto da lei permite observar, entretanto, que os sentidos atribuídos a direitos e regalias no contexto local não correspondem àqueles acionados na legislação, ainda que se articulem com eles. Isso porque, como vimos acima, enquanto regalia é frequentemente acionada para se referir a direitos previstos formalmente, direito pode se referir a um benefício sem previsão legal. A falta de delimitação clara entre as categorias é evidenciada igualmente pelo fato de a mesma prática institucional ser formulada por diferentes pessoas como direito ou regalia. Estabelecendo um paralelo com a pesquisa de Figueira (2007) no Tribunal do Júri do Rio de Janeiro, é possível identificar uma "instabilidade semântica" das noções de direitos e regalias no contexto local, que são significadas de modos distintos por diferentes interlocutores/as e, em alguns momentos, têm seus sentidos canônicos invertidos ou aparecem mesmo como categorias intercambiáveis (ou fungíveis). Essa indefinição traduz, em grande medida, um padrão de desrespeito aos direitos legais de pessoas presas no ambiente carcerário (LEMOS, 2018).

A naturalização da violação dos direitos formais de pessoas presas não pode ser desassociada do filtro discriminatório, racista e classista, da seletividade criminal no Brasil. Isso porque a população presa é composta, em grande medida, por grupos sociais marginalizados - especialmente jovens negros/ as que moram em periferias urbanas - cujos direitos foram historicamente negados. A relação de continuidade entre o padrão de desrespeito aos direitos desses grupos dentro e fora da prisão é um reflexo da conexão entre distribuição desigual de direitos e atribuição diferencial de status social no âmbito de instituições públicas e da sociedade civil (OLIVEIRA, 2011, 2018) e do processo de construção da cidadania no Brasil, que se sedimentou na desconsideração de pessoas negras, indígenas, pobres e/ou moradoras de favelas e periferias urbanas como sujeitos de direitos. 
Levando em consideração esse aspecto, a instabilidade semântica ou fungibilidade entre as categorias direitos e regalias é especialmente significativa porquanto inserida em um contexto em que os privilégios dos estratos superiores da população são formulados como direitos, enquanto os direitos formais de segmentos marginalizados são tratados como privilégios, permitindo que sejam desconsiderados. Como ressaltado por Helena, para a "polícia, tudo que beneficia as presas é regalia”. Sua fala ganha sentido em um cenário em que os direitos de pessoas presas previstos formalmente na Constituição Federal e na Lei de Execução Penal são sistematicamente desrespeitados e, quando cumpridos, são formulados, tanto localmente quanto pela sociedade civil, como regalias. Ao mesmo tempo, alguns privilégios conquistados naqueles ambientes acabam sendo formulados como direitos, não porque efetivamente correspondam a um direito formal e abstrato, mas porque entraram na esfera de expectativas de tratamento construídas localmente. Helena não tem, de acordo com as regras internas, direito de mudar de ala. Mas, sendo essa uma prática local corrente, torna-se também objeto de uma demanda de direito.

O sentido fluido das categorias direitos e regalias parece estar associado, outrossim, à ausência de critérios compartilhados para orientar sua distribuição. Nesse sentido, as normas que disciplinam o mundo das cadeias locais consistem em regras não escritas que, além de não serem publicizadas em regulamentos expressos, sendo aprendidas na prática do dia a dia, não são sequer estáveis, ou seja, têm diferentes instâncias prescritivas provisórias (a casa, o plantão ou mesmo determinado agente ${ }^{15}$ ) e são aplicadas por meio de métodos seletivos particulares irregulares (LEMOS, 2018).

Relatos de campo permitem verificar esse modo de produção e aplicação das regras sobre distribuição de direitos e regalias nessas cadeias. Alguns interlocutores/as associam a concessão de regalias (ou direitos) ao bom comportamento. Para Ana, por exemplo, "algumas regalias, também, que você tem por mérito seu". De modo similar, Luciano, quando puxava pena no Cascavel, chama atenção a que, ao requerer sua alocação no bloco $\mathrm{E}^{16}$ com base em sua

\footnotetext{
${ }^{15}$ Casa se refere à administração prisional e plantão aos funcionários que estão de plantão naquele dia.

${ }^{16}$ O bloco E é o único na unidade de Cascavel em que os homens têm oportunidade de estudar.
} 
vida pregressa na cadeia, não lhe foi dado nenhum argumento concreto para a recusa. Ou seja, por mais que se identificasse como um interno de bom comportamento, tendo inclusive sempre trabalhado durante seu tempo preso, nunca conseguiu ir para o Bloco da Escola para estudar. Certa vez, ao inquirir um dos funcionários sobre o motivo de sua não alocação nesse bloco, Luciano narra que: "ele não fez nem questão de ir lá olhar se tinha alguma denúncia de lá de dentro contra mim, não, ele só 'se tu tá aqui é porque tu... tu só sai daqui quando eu quiser"'. Para ele, havia situações em que o advogado ou a família do preso teriam de ter uma relação pessoal com o diretor da unidade para conseguir ter seus pedidos atendidos: "Eu vi cara chegando assim, amigo meu, que tinha influência de família e tudo, e em poucos dias arrumaram".

A distribuição arbitrária de direitos e regalias aparece não estar associada apenas à intervenção pessoal de advogados e familiares, mas também ao fato de o/a interno/a correr com os canas, ou seja, colaborar com a polícia. Desse modo, algumas pessoas receberiam tratamento privilegiado dentro da cadeia como recompensa por passar informações sobre a $\mathrm{massa}^{17}$ para a polícia: "Que a gente tem esse detalhe aqui, que tem pessoa que consegue as coisas muito rápido aqui dentro, e às vezes a gente fala: 'como diz o ditado da cadeia, tá correndo com os canas"' (Denise).

Desse modo, por ausência de critérios compartilhados, refiro-me à arbitrariedade, ao autoritarismo e personalismo que orientam a distribuição de direitos e regalias nas cadeias locais. Isso não significa que não existam critérios para a distribuição destes, ou mesmo que não se possa identificar a reiteração de alguns critérios - como as relações pessoais com a polícia e a colaboração de alguns presos (os caguetas) com esta - na prática dessa distribuição, mas apenas que, do ponto de vista de seus destinatários, muitas vezes não está claro quais são, como e quando esses critérios serão acionados. Ou seja, mesmo quando é possível identificar a existência desses critérios, estes são aplicados de modo irregular e instável, aspecto ilustrado pela história de Helena. Do seu ponto de vista, de acordo com os critérios informais (ter bom

\footnotetext{
17 A massa compreende o espaço normal de circulação dos presos/as. Aparece em contraposição a seguro, que são locais destinados a presos/as cujo comportamento está em desacordo com as moralidades locais.
} 
comportamento e estar trabalhando) que ela acreditava orientar a mudança de ala, ela faria jus a esse direito e, quando este lhe foi negado, ela não sabia informar os critérios que fundamentavam a recusa.

Assim pode-se identificar, para além de um de padrão de violação a direitos formais, a distribuição desigual de direitos e benefícios dentro do contexto prisional. Nesse caso, entretanto, os "privilégios" distribuídos correspondem, muitas vezes, a direitos formais aos quais todas as pessoas presas deveriam ter acesso.

Espero ter demonstrado que os modos de acionamento das categorias direitos e regalias neste contexto etnográfico traduzem, por um lado, a naturalização de um padrão de desrespeito aos direitos formais de pessoas presas que está associado à desconsideração desses cidadãos que, em sua maioria, fazem parte de grupos historicamente marginalizados no Brasil. Por outro, a percepção de arbitrariedade no modo como se distribuem direitos e regalias aponta para um modelo autoritário de produção e aplicação de regras no espaço da cadeia que está associado à ausência de critérios compartilhados para orientar as diferenças de tratamento no âmbito da esfera pública no Brasil (OLIVEIRA, 2011).

É possível traçar um paralelo entre a percepção dos/as nativos/as sobre as concepções de justiça na cadeia e a associação que Honneth (1992, 2003) estabelece entre privação de direitos e a desconsideração da identidade de sujeitos. Isso porque o próprio modo como direitos e regalias são representados pelos/as interlocutores/as está imbricado com relatos sobre experiências de injustiça nos contextos que apontam para a desconsideração dessas pessoas como sujeitos de direitos, o que implica não apenas a violação sistemática de seus direitos fundamentais, mas sua exclusão dos critérios que informam a distribuição desses direitos. Nesse sentido, Honneth (2003, p. 216) destaca que a experiência de desconsideração que pode surgir em contextos de negação de direitos tem "associação com o sentimento de não possuir o status de um parceiro da interação com igual valor, moralmente em pé de igualdade".

Como destaquei anteriormente, no contexto brasileiro, há uma particularidade quando se reflete sobre a dimensão moral da cidadania a partir da 
perspectiva de relatos de experiências de desconsideração. Os/as cidadãos/ ãs que são, com maior frequência, alvo de violência no âmbito do Estado e da sociedade civil fazem parte de grupos sociais cujos direitos individuais e sociais são historicamente violados e negados. A associação entre as lesões às dimensões morais e legais da cidadania no Brasil revela, portanto, uma grave situação de "déficit de cidadania" que atua de modo discriminatório, já que o não reconhecimento desses cidadãos como pessoas dignas autoriza e naturaliza, aos olhos do Estado e da sociedade civil, o sistemático desrespeito a seus direitos e os atos de violência contra eles(as) praticados (OLIVEIRA, 2011).

\section{Humanidade denegada}

Gostaria de examinar agora os modos de acionamento da categoria humano nesse campo etnográfico, demonstrando sua associação com as percepções dos/as interlocutores/as sobre formas de tratamento nesses locais. Ainda que as práticas em si variem um pouco de presídio para presídio, elas assumem para os/as interlocutores/as significados semelhantes, sendo frequentemente percebidas como formas de humilhação e constrangimento que rebaixam seu valor e estima sociais por meio da relativização (ou negação mesmo) do seu status de humano.

Em todas as nossas interações, interlocutores/as chamaram atenção para as péssimas condições de acomodação, higiene e alimentação nos presídios locais, principalmente nos locais de cumprimento de pena no regime fechado e de detenção provisória. Relatam que, sem iluminação e ventilação adequadas, as celas são úmidas e frias no inverno e quentes e abafadas no verão, além da frequente incidência de mofo. As camas - as jegas - são feitas de concreto, com apenas um fino colchão em cima; o banheiro - o boi - é um buraco no chão no fundo da cela, sem descarga ou assento; o chuveiro, um cano de água gelada localizada logo acima do boi. À noite, aqueles/as que não têm jegas geralmente o número de moradores da cela é duas ou mesmo três vezes maior que o de camas - ou não encontram com quem dividir uma, estendem seus colchões no chão da cela para dormir. 
Outro ponto de descontentamento entre os/as interlocutores/as se refere à alimentação nos presídios, que é fornecida por empresas terceirizadas. Contam que é comum a comida vir crua, estragada ou azeda: É a pior xepa ${ }^{18}$, acho que nem porco não come aquela xepa (Helena). Durante uma de nossas conversas, Luciano narrou que, enquanto esteve preso no Cascavel, frequentemente os homens reclamavam com a polícia sobre a xepa, pedindo que fosse trocada. Entretanto, além de não terem seus pedidos atendidos, contou que houve ocasiões em que aqueles que haviam reclamado foram depois colocados no castigo por incentivaram a massa.

As formas de chamamento nas cadeias era igualmente um aspecto recorrente nas minhas conversas com interlocutores/as, o que pude também observar durante minhas incursões a campo. Predominam as formas impessoais de chamamento, como interno/interna ou preso/presa, e são comuns as ofensas e xingamentos, como nojenta, porca, vagabundo, entre outros. Sobre o período em que ficou preso no Centro de Detenção Provisória (CDP), Francisco destacou: "você precisa ver que judiação, chega xingando de mulambo, de tudo quanto é nome. Xinga e bota lá embaixo" (Francisco).

Narrativas de violência sistemática durante as revistas das celas - por meio do uso de spray de pimenta, do descarte de comida dentro do boi e da destruição de pertences pessoais e colchões - e as intervenções no pátio de banho de sol - mediante o uso indiscriminado de balas de borracha, cassetete e bombas de efeito moral - são igualmente marcantes. Luís, que passou três anos e sete meses preso provisoriamente no CDP, relatou a ocasião de uma invasão da DPOE no pátio em que foram obrigados/as a permanecer sentados debaixo do sol por várias horas:

"Deixa a gente ali às vezes horas no pátio, igual uma vez que a gente
ficou das nove da manhã até as cinco horas da tarde no pátio sem po-
der se mexer. Inclusive até a posição que eles colocam a gente é cons-
trangedora, né, porque eles colocam a gente sentado, com a cabeça en-
tre as pernas, aí você imagina, ficar de baixo dum solzão de rachar das

\footnotetext{
${ }^{18}$ Marmita onde vem a refeição.
} 
nove manhã até cinco horas da tarde? No outro dia tava todo mundo despelando" (Luís).

A adoção do uniforme na Colmeia, a partir de 2014, era outro ponto de grande insatisfação entre minhas interlocutoras, que, de modo unânime, avaliavam negativamente a medida. O uniforme fornecido pela instituição era uma blusa branca com as mangas laranjas e a estampa interna na frente, em letras laranjas garrafais, e uma bermuda ou calça laranjas também. Além de considerarem o modelo e cor feios, minhas interlocutoras relatavam que o tecido do uniforme era de má qualidade, de modo que se danificava com facilidade, o que acarretava represálias institucionais para as mulheres, que levavam por isso uma ocorrência ${ }^{19}$.

Pode-se notar que as narrativas dizem respeito não apenas a situações de ataques à integridade física de interlocutores/as, mas, principalmente, à sua integridade moral. O acionamento de categorias como humilhação, constrangimento e judiação nos relatos sobre essas experiências revelam que com frequência suscitam sentimentos de rebaixamento moral e vexação, que atingem diretamente importantes dimensões de senso de identidade e dignidade dessas mulheres e homens.

Em relação ao primeiro aspecto, as formas de tratamento descritas encontram ressonância com o que Goffman (1974) nomeou de métodos de "mortificação do eu" em instituições prisionais, ressaltando o papel que exercem no processo de redefinição do "self" ao longo do período de segregação. No cenário nacional, a partir do relato de sua própria experiência, Lima (2001, p. 44) chamou de "desarticulação da personalidade do preso" os procedimentos institucionais que acompanhavam a chegada às prisões, destacando seu importante papel no âmbito do sistema penitenciário. No contexto etnográfico ora analisado, esses procedimentos institucionais perturbam o senso de integridade pessoal de diferentes modos: i) privando-lhes de marcas distintivas de sua personalidade - nome, aparência, posse de objetos pessoais -, substituindo-as por equivalentes depreciativos e anônimos, como os xingamentos,

\footnotetext{
19 Anotação de uma falta disciplinar.
} 
a alcunha preso/a ou interno/a, uniformes feios e de má qualidade, cortes de cabelo padronizados ${ }^{20}$; ii) coletivizando a autoria de seus atos e as respectivas punições (Lá eles têm uma lei de que um paga por todos), a exemplo do que ocorre em momentos de intervenção nos pátios; iii) retirando-lhes o senso de privacidade por meio da alocação em celas lotadas com instalações sanitárias abertas e compartilhadas; iv) expondo-os a condições de higiene precárias, o que se verifica pela insalubridade das celas, ausência de instalação sanitária adequada e pelo fornecimento de alimentação velha e estragada. A identidade prévia ao encarceramento é assim sobreposta, do ponto de vista institucional, pelo estigma de preso/presa. No caso dos meus interlocutores/as, fica claro que essa sobreposição é percebida como constrangedora e significada como uma imposição externa degradante.

Esse fenômeno aponta para o processo de atribuição e incorporação da identidade de preso/a no contexto prisional. Esse processo é inerente à própria institucionalização que caracteriza a privação de liberdade, de modo que é vivido, de forma mais ou menos intensa, por toda pessoa submetida a uma pena de prisão, pois, uma vez encarcerada, a pessoa vive um processo de assujettissement (sujeição) (FOUCAULT, 1997) por meio do qual se lhe atribui a identidade de preso/a.

Se preso/a, de forma semelhante a bandido, é um rótulo social que tende a se sobrepor a todos os outros aspectos da identidade de uma pessoa - sendo frequentemente associada a outras identidades socialmente "degradadas": o pobre, o analfabeto, o vagabundo, o usuário de drogas etc. (MISSE, 2010) -, é importante observar que esse estigma recebe significados distintos em contextos diferentes. É interessante, por exemplo, a ressignificação positiva dessa categoria em cadeias de São Paulo por meio da organização política de pessoas presas em grupos como o Primeiro Comando da Capital - PCC (BIONDI, 2009; MARQUES, 2010), que busca inverter a lógica degradante dos processos institucionais de redefinição da identidade.

Diferentemente, o trabalho de campo no Distrito Federal demonstrou que os procedimentos institucionais de desarticulação da identidade e atribuição do

\footnotetext{
${ }^{20}$ Os homens presos são obrigados a manter seus cabelos raspados, sob pena de receberem um castigo.
} 
rótulo preso/a ou interno/a estão associados ao processo de construção social do "sujeito criminoso" (MISSE, 2010) nesse contexto e são, de modo predominante, vividos como uma forma de violência pelos/as interlocutores/as. As narrativas deixam evidente o caráter opressor e coercitivo da atribuição dessa identidade. Nesse sentido, Luís falou-me sobre seu desejo de se desassociar desses estigmas para se sentir mais valorizado:

"Na Senasp [Secretaria Nacional de Segurança Pública] também era bom [...]. Nossa, todo mundo me respeitava, ninguém me tratava como preso. Porque não tem coisa pior do que você tá sempre, mesmo que indiretamente, você tá sendo lembrado do seu passado, né? Quando você tem desejo de mudança e você vê o tempo todo por meio das atitudes das pessoas, as pessoas, tipo, tá tentando te lembrar: 'oh, você é diferenciado porque você é preso', ai é constrangedor, né? Lá não, me tratava perfeitamente, tudo que faziam me incluíam [...]. Aí você se sente bem-valorizado, né? Você começa até a esquecer de quem, de onde você veio" (Luís).

A reivindicação dos atores sociais de que sua identidade seja reconhecida para além dos estigmas bandido e presalpreso revela que percebem estes últimos como humilhantes, ofendendo seu valor e estima sociais. É recorrente, desse modo, a associação, pelos/as interlocutores/as, entre essas identidades sociais e categorias depreciativas, como lixo da sociedade, bicho, animal, cachorro, que frequentemente aparecem em contraposição a humano e gente. Aline, por exemplo, ao contar sobre o tempo em que puxou pena na Colmeia, disse-me que considerava muito desumano a forma de tratamento nessa cadeia:

"Queria tratar a gente como lixo, como animal, como resto dos restos da sociedade. Sabe, que querendo ou não você fica ali como o resto, o lixo da sociedade, excluído de tudo e de todos" (Aline).

Os/as interlocutores/as identificam, portanto, no contexto das cadeias locais, um processo de relativização ou mesmo negação de seu status de humano 
e gente, categorias que dizem respeito não às suas características biológicas, mas à dimensão moral de sua identidade. Para Denise, o não reconhecimento de sua humanidade nesse contexto está associado ao própria rótulo de preso:

"As pessoas que trabalham do outro lado, eles acham que a gente não é humana pelo fato de tá aqui dentro. As pessoas do outro lado que eu falo no caso são os polícias, né? Eles acham que, porque a gente é preso, a gente tem que fazer o que eles quer e tal, e a gente não é humano, a gente não pode sentir cansaço, a gente não pode sentir dor" (Denise).

De modo semelhante, Freire (2010), em sua análise sobre padrões de sociabilidade na cidade do Rio de Janeiro, identifica naquele contexto um "regime de desumanização" que consiste em um "conjunto de operações morais que parece criar um consenso em relação à ideia de que nem todos são dignos de serem incorporados na humanidade comum" (FREIRE, 2010, p. 128), permitindo que o próprio status de "ser humano" seja socialmente questionado. Parece-me que as formas de tratamento nas cadeias locais produzem igualmente um "regime de desumanização" ao relativizar o status de humano e gente de mulheres e homens presos e negar-lhes a substância moral de pessoas dignas ${ }^{21}$ (OLIVEIRA, 2011).

Berger (1983), em sua análise sobre a transformação da noção de honra na ideia de dignidade na passagem entre o antigo regime e a sociedade moderna, ressalta que, diferentemente da honra, que está atrelada a posições sociais, a dignidade diz respeito ao indivíduo em si, independentemente de sua posição na sociedade. A dignidade seria, portanto, universal, inerente à humanidade, transcendendo papeis ou normas socialmente construídos. Se aceitarmos essa formulação como válida, a relativização da humanidade, percebida pelos/as interlocutores/as, pressupõe também a negação de sua dignidade, aspecto para o qual eles/as próprios/as chamam atenção em suas

\footnotetext{
${ }^{21}$ Ou seja, a "substância moral' da pessoa, a qual seria constitutiva dos direitos de cidadania associados ao reconhecimento da dignidade ou à consideração à pessoa do cidadão" (OLIVEIRA, 2011, p. 77).
} 
falas: "você se sente um dos piores naquele lugar. Você perde sua dignidade, perde sua família, perde tudo" (Anderson).

O acionamento da categoria humano nas cadeias locais chama atenção, portanto, por sua associação com formas de negação da identidade e dignidade dos/as interlocutores/as, que frequentemente se articulam a sentimentos de humilhação e rebaixamento. Nesse aspecto, parece-me central o não reconhecimento desses cidadãos, na esfera do Estado e da sociedade civil, como pessoas dignas que merecem respeito, permitindo um padrão lastimável de tratamento nas prisões brasileiras de modo geral.

É interessante notar, outrossim, que a categoria humano acionada no contexto local não é compreendida como um conceito biológico, como qualidade inerente a toda pessoa da espécie humana. Humano é aqui formulado como categoria social que diz respeito não às características biológicas de uma pessoa, mas a construções sociais a respeito de seu valor moral.

Se consideramos a história do processo colonizador em nosso país que se sedimentou no massacre, extermínio e escravização das populações nativas e de povos africanos - não é possível falar de regimes de desumanização no Brasil sem chamar atenção para sua íntima associação com as dimensões raciais da noção de humano. Nesse sentido, Mbembe (2014, p. 157), ao analisar os discursos raciais suscitados nos países de colonização europeia nos continentes americano e africano no século XIX, ressalta que "De fato, a maior parte das teorias políticas do sec. XIX estabeleceu uma estreita relação entre sujeito humano e sujeito racial". O autor destaca, assim, a centralidade da dimensão racial no então debate acerca do que caracterizaria a humanidade e de se os povos não brancos - que na economia política do mercado escravocrata figuravam na condição de objetos fariam (ou não) parte de uma humanidade universal. Uma das respostas que se ofereceu à época a essa questão se baseava justamente no princípio de uma "diferença fundamental" entre povos brancos e povos negros e indígenas, o que implicava a exclusão destes da "esfera da cidadania humana total" (MBEMBE, 2014, p. 157). 
A desumanização histórica de sujeitos negros e indígenas está imbricada, do mesmo modo, com as construções sociais acerca do indivíduo criminoso e de sua "periculosidade". Nesse sentido, Mbembe (2014, p. 144) ressalta que "o medo racial, em particular, foi desde sempre um dos pilares da cultura do medo intrínseca à democracia liberal". Assim, no século XIX, quando o Brasil vivia os conflitos e discussões concernentes à abolição da escravatura, surgiram diferentes teorias sobre a miscigenação e as relações raciais. Schwarcz (1987) ressalta que, nesse contexto, ganhou especial força a perspectiva segundo a qual a miscigenação da população brasileira seria um sinal de degenerescência. Nina Rodrigues (1894), por exemplo, considerava que a inferioridade biológica da "raça negra" podia ser estabelecida fora de qualquer dúvida científica e sustentava a necessidade de defender a "raça branca" superior da ameaça representada pelas "raças conquistadas" ou "submetidas", ontologicamente perigosas e, portanto, alheias às noções de livre arbítrio e responsabilidade penal.

O estigma preso/presa se sobrepõe e sintetiza, portanto, um emaranhado de subjetividades historicamente desumanizadas em nosso país - o negro, o pobre, os moradores das periferias urbanas, o "criminoso". Nesses regimes de desumanização, o racismo é um pressuposto necessário, na medida em que atua como princípio hierárquico que estrutura a repartição moral entre sujeitos que merecem ter sua vida preservada e sujeitos "matáveis" (MISSE, 2010), cuja vida biológica e política representam um perigo ao corpo social e, portanto, não merece ser preservada, podendo ser expostos, direta ou indiretamente, à morte civil ou física (FOUCAULT, 1997).

Acredito que os dados de campo aqui analisados permitam concluir que as percepções sobre formas de tratamento nas cadeias traduzem experiências de desconsideração. Articulando esses achados com a filosofia moral de Honneth (2003, 1992), que diferencia entre três modos fundamentais de desconsideração, é possível dizer que as formas de tratamento descritas pelos interlocutores/as - e observadas por mim em campo - evidenciam tanto agressões à integridade física desses atores sociais quanto degradações e ofensas morais que rebaixam seu valor e estima. Como ressaltou o autor, a exposição a essas formas de desrespeito é frequentemente traduzida por "reações emocionais 
negativas", como a vergonha, a vexação e mesmo a ira. Assim, é interessante acionar expressões como constrangimento, vergonha, humilhação e revolta ao narrar essas experiências.

\section{Direitos humanos}

Na descrição apresentada sobre o modo de acionamento da categoria direitos humanos pelos interlocutores/as, evidencia-se sua articulação com relatos de violações a direitos e de agressão contra sua integridade física e/ou moral. Os casos de Cleonice e Francisco talvez sejam os mais ilustrativos a esse respeito, pois neles a primeira violação, que justificaria a intervenção dos direitos humanos, é seguida por uma segunda, que tem o objetivo seja de impedir essa intervenção, seja de punir aqueles/as que ousam falar a verdade aos direitos humanos. Além desses relatos, outras pessoas também narraram ocasiões em que elas mesmas ou um/a conhecido/a receberam um castigo após a família fazer uma denúncia aos direitos humanos, o que acabava desestimulando as famílias a proceder desse modo. Revelam, assim, os mecanismos institucionais implementados, seja para maquiar a gravidade das violações nas cadeias, seja para impedir ou desestimular que se formulem demandas e reclamações perante os direitos humanos.

Aqui, mais uma vez fica patente a dimensão da desconsideração, cuja expressão simbólica mais significativa é a formulação dos direitos humanos enquanto sujeitos. Parece-me que, em parte, essa personificação se articula com o contexto em que as três categorias -direitos, humanos e direitos humanos - são mais frequentemente acionadas, que é marcado por uma experiência radical de desconsideração, caracterizada pela exposição sistemática aos três modos fundamentais de ataque à integridade pessoal identificados por Honneth (1992).

Como sugeri, a formulação dos direitos humanos como sujeitos é uma representação bem clara de que estes não são concebidos como direitos abstratos, como objetos dos quais seriam titulares todos os seres humanos. Mas, em um contexto de completo esvaziamento do conteúdo dos direitos formais de pessoas presas - em que esses direitos são frequentemente concebidos como 
regalias e distribuídos de acordo com critérios não compartilhados - parece-me congruente que os direitos humanos não sejam formulados como direitos universais abstratos, mas como aquelas pessoas que intervêm a seu favor. Ao representar nesses termos os direitos humanos, fica evidenciado não apenas o esvaziamento do conteúdo desses direitos, mas também a dimensão personalista da sua distribuição, que aqui assume uma tradução quase literal por meio da transformação, no plano linguístico, dos direitos humanos em sujeitos.

Do mesmo modo, é significativo que essa personificação se dê em um contexto em que os/as interlocutores/as identificam uma relativização ou denegação do seu status de humano. A relativização do status de humano de pessoas presas no âmbito da instituição prisional não pode ser desassociada, portanto, de seu não reconhecimento como sujeitos de direitos humanos. Isso porque a denegação do status de humano é o que permite e perpetua as práticas institucionais que excluem essas pessoas da esfera de proteção desses direitos, seja escamoteando as violações que ocorrem nesse contexto, seja punindo aqueles/as que recorrem aos direitos humanos. Por conseguinte, a própria existência dos direitos humanos - entidade abstrata que se pretende universal - está, no âmbito da cadeia, adstrita a sua presença física, corporal.

A encarnação dos direitos humanos é aqui emblemática, pois escancara uma falha fundamental na sua concepção jurídica, qual seja a pressuposição de que a humanidade é dada, de que esse é um atributo que se estende de modo automático para todos/as aqueles/as que são da espécie humana. Ignora-se, com isso, que a humanidade não é apenas um conceito biológico, mas uma categoria social que tem conteúdo moral, um status que é negado ou concedido, a depender de quem esteja do outro lado do espectro e de se este/a é ou não incluído/a em determinada concepção de comunidade moral. Nesse sentido, é preciso estar atento aos processos sociais e políticos de desumanização de pessoas e grupos sociais que possibilitam que sejam excluídos do universo daqueles protegidos pelos chamados direitos humanos.

Como indiquei acima, no Brasil, essa experiência radical de desconsideração está intrincada a um processo histórico de construção social de identidades degradadas (MISSE, 2010) - do bandido, do preso, do criminoso - que tem um 
forte viés excludente (OLIVEIRA, 2011) de cunho racista e classista. A exclusão dessas pessoas do "regime de humanidade comum" (FREIRE, 2010) - ou "esfera da cidadania humana total" (MBEMBE, 2014) - indica que, no Brasil, status social está diretamente associado à negação, a determinadas parcelas da população, da "substância moral de pessoas dignas" (OLIVEIRA, 2011). Uma vez que sequer são reconhecidas como sujeitos de direitos ou mesmo como humanas, também não alçam a condição de sujeitos de direitos humanos. No lugar, são os direitos humanos que são humanizados, encarnados por sujeitos, assumindo a forma corpórea e sendo materializados como presença física.

\section{DIREITOS HUMANOS, ALTERIDADE E RECONHECIMENTO SOCIAL}

Espero ter demonstrado, no item anterior, de que modo a personificação dos direitos humanos está associada a uma experiência radical de desconsideração vivida no âmbito das cadeias do DF, em que aspectos fundamentais da integridade pessoal são sistematicamente perturbados no âmbito institucional. Para concluir, gostaria de tecer algumas reflexões sobre os sentidos simbólicos da encarnação dos direitos humanos e de sugerir o potencial dessa concepção como vetor de reconhecimento social e de concretização de direitos no contexto da privação de liberdade no Brasil.

A humanização dos direitos humanos é especialmente interessante porque ocorre no contexto de um regime de desumanização. Desse modo, se humano é um status que pode ser concedido ou denegado, o processo de desumanização nesse contexto não é totalizante. Ele se dá no âmbito de relações de poder que não são estáticas e tampouco se caracterizam como dominação global de um grupo sobre o outro (FOUCAULT, 1997). Isso não significa que não se produzem efeitos de sujeição e coerção, mas aqueles que são, de modo predominante, submetidos a esses efeitos continuam em cena, como sujeitos ativos, dispostos a subverter episódios de opressão em momentos de resistência (CONLEY; O’BARR, 2005). Essa resistência não corresponde a um fenômeno em larga 
escala, a uma subversão profunda da ordem, mas a essas inversões esporádicas e pontuais das relações de dominação por aqueles que geralmente são a elas submetidas.

O regime de desumanização nas cadeias locais, que é exercido de modo mais violento por agentes estatais em relação a pessoas presas, é assim atravessado por focos de resistência que invertem, ainda que de modo pontual e precário, seus efeitos de opressão. Em contraposição, portanto, a esse regime de desumanização, os direitos humanos passam pelo processo inverso, sendo humanizados por meio da sua encarnação em sujeitos, que são então incluídos no círculo de reciprocidade desses atores sociais. Chama atenção, nesse sentido, que os direitos humanos não sejam concebidos como quaisquer sujeitos; são, nas palavras de Cleonice, as "pessoas que são a favor dos presos e das presas" e "tipo, defende a gente, se a gente tá sendo maltratado".

A personificação dos direitos humanos está inserida, desse modo, em uma sensibilidade jurídica (GEERTZ, 1998) que reflete não apenas os efeitos negativos de coerção produzidos por um cenário de violação aos direitos e de desumanização de pessoas presas, mas também traduz um determinado esforço de se contrapor a esses efeitos. Isso porque a humanização dos direitos humanos pode ser interpretada como uma estratégia para resistir contra esse cenário, pois permite subverter ou criar brechas neste regime de desumanização, transformando a experiência do reconhecimento denegado em uma oportunidade de romper o isolamento e de se reconhecer no outro. Assim, ao incorporar os direitos humanos em sujeitos concretos, delineia-se um senso de justiça em que tem precedência o elo social e que tem o potencial de atuar como vetor de reconhecimento social.

Como destaquei, nessa concepção, os direitos humanos não são representados como propriedades, como atributos de mulheres e homens. No lugar de uma relação de propriedade, titularidade ou posse, a relação com os direitos humanos é aqui representada como uma relação entre pessoas, entre sujeitos, na medida em que se reconhecem uns aos outros como humanos. Por esse ângulo, é o elo social, e não a titularidade, que configura a relação entre sujeitos e direitos. Os direitos humanos saem, assim, do plano da abstração, do ideal, e 
sofrem uma espécie de secularização que os concretiza, enquanto sujeitos, no campo mundano das relações.

A concepção de direitos humanos aqui analisada se situa, portanto, no âmbito de determinada sensibilidade jurídica, que se produz no contexto das cadeias locais e se pauta não por um ordenamento jurídico estatal, mas pelas normatividades que atravessam as relações interpessoais. As demandas de respeito e consideração são princípios estruturantes dessa moralidade comunitária ${ }^{22}$ (OLIVEIRA, 2018), que se delineia a partir de uma experiência radical desconsideração. O valor aqui atribuído ao elo social é especialmente significativo, pois só por meio dos vínculos construídos entre parceiros/as de interação é possível romper o isolamento - agravado neste caso pela segregação - e de sentir sua própria identidade (GODBOUT, 1998).

Dentro dessa perspectiva, é reveladora a importância atribuída às visitas de amigos e familiares nas cadeias. A presença das visitas é fundamental não apenas para a subsistência material nas cadeias, mas, em grande medida, para a preservação dos vínculos sociais anteriores ao encarceramento, o que permite resistir ao sofrimento infligido por essa experiência. Esses elos sociais exercem uma função protetiva para as pessoas presas, aspectos presentes nas falas de Cleonice, Francisco e Luciano aqui transcritas, que enfatizam a importância das visitas para romper o isolamento imposto pela segregação e para exercer uma vigilância sobre atos de violência ou violações a direitos de pessoas privadas de liberdade.

Portanto, para que a atuação dos direitos humanos possa se conformar à sensibilidade jurídica vigente no âmbito dessa moralidade comunitária, realizando seu potencial como vetor de reconhecimento social e de concretização de direitos, é necessário que incorpore a dimensão interpessoal do direito em sua prática. Sugiro, para tanto, que essa prática seja pautada pelo que Segato (2006) chamou de "ética da alteridade", caracterizada pela abertura ao outro e pela disponibilidade de ser interpelado por este. Para Segato (2006), essa "ética

\footnotetext{
${ }^{22}$ Cardoso de Oliveira (2018: 58) diferencia entre uma "moralidade societária (com referência à normatividade nas relações entre todos os cidadãos, contando com o respaldado do Estado) e uma moralidade comunitária (com referência à normatividade nas relações interpessoais)".
} 
da alteridade" corresponde não a conteúdos abstratos enumeráveis, mas a um desejo ou impulso de contestarmos os códigos morais e legais que fundamentam e naturalizam relações de abuso e desigualdade dentro e fora do contexto estatal. No caso de pessoas presas, essas relações estão intrincadas a uma estrutura social desigual e racista que se articula a processos de desumanização que tipificam - de acordo com o status social - aqueles/as dignos ou não de serem incorporados na humanidade comum.

De certo, não vislumbro plenamente essa prática na descrição dada pelos/as interlocutores/as da atuação dos direitos humanos. O retrato dado por Cleonice, por exemplo, demonstra que, em algumas ocasiões, as condições dessa atuação inviabilizam que se possa verificar e intervir adequadamente em situações de tortura ou violações a direitos na cadeia e podem mesmo expor as pessoas presas a outras formas de agressões a direitos. Esse aspecto evidencia a necessidade de que órgãos de proteção a direitos humanos tenham autonomia, de modo que possam garantir segurança, privacidade e anonimato, imprescindíveis para que as pessoas presas possam falar abertamente sobre as violações de direitos nas cadeias, não sofrendo por isso - depois de os direitos humanos virarem as costas - represálias e maiores violências. Do mesmo modo, é necessário que possam realizar visitas não programadas, que não sejam previamente informadas às administrações penitenciárias, evitando a possibilidade de maquiar as condições de vida nesse espaço.

Acredito que só seja possível aprimorar essa atuação e construir uma prática que subverte a lógica da desumanização se os direitos humanos forem mobilizados por determinada pulsão ética que não permite se acomodar com esse cenário; ou seja, por uma "ética dos desconformes; [...] dos que têm disponibilidade quanto à diferença, ao novo e ao outro [...]; dos sensíveis às margens [...] e às vítimas [...]" (SEGATO, 2006, p. 223).

Do ponto de vista da autora, é essa pulsão ética que permite explicar o movimento de expansão dos direitos humanos no plano internacional e nacional. Trazendo essa ideia para o contexto da minha análise, uma prática pautada por uma ética da alteridade implicaria que os direitos humanos não apenas dirigissem seu olhar para este outro - as pessoas presas - mas que também se sujeitassem ao 
olhar do outro. Agentes de direitos humanos devem, portanto, estar dispostos a serem interpelados por esse olhar e a reconhecer sua responsabilidade - "o sentido preciso de responder ao outro" - perante ele, "admitindo sua interpelação e seu pedido de prestação de contas" (SEGATO, 2006, p. 226). É o olhar do outro que lança dúvidas sobre e desloca nossas certezas e valores em um movimento perpétuo cujo fim último seria não se acomodar e fugir da automação que reifica e invisibiliza a desigualdade, o sofrimento, a morte e a violência contra aquele/a "que se encontra do outro lado das muralhas de contenção da 'normalidade' moral do grupo" (SEGATO, 2006, p. 223). Acredito que, movidos por uma ética da alteridade, os direitos humanos, situados no plano concreto das relações interpessoais, podem representar um importante vetor de reconhecimento social e de concretização dos direitos no contexto da privação de liberdade no Brasil.

Argumentei neste texto que as concepções de direitos humanos formuladas por pessoas que puxam pena no Distrito Federal apresentam uma singularidade, já que, diferentemente de sua concepção jurídico-legal, são formulados não como objetos dos quais seriam titulares, mas como sujeitos que atuam no plano concreto das relações intersubjetivas. A partir dos dados encontrados em campo, associei a personificação dos direitos humanos no âmbito das cadeias locais a uma experiência radical de desconsideração, que é traduzida pelo modo como as categorias direitos e humanos são acionadas pelos atores sociais. A articulação entre essas categorias revela um esvaziamento do conteúdo dos direitos formais das pessoas presas - e a ausência de critérios compartilhados para orientar a distribuição de direitos e regalias - e processos de desumanização que desarticulam a identidade dos interlocutores/ as e os/as inferioriza no plano da dignidade. Para concluir, argumentei que essa concepção de direitos humanos se situa no âmbito de uma moralidade comunitária permeada por uma sensibilidade jurídica em que o elo social tem precedência. Propus, desse modo, que os direitos humanos têm o potencial de funcionar como vetor de reconhecimento social e de concretização de direitos no contexto da privação de liberdade no Brasil, subvertendo o padrão de desrespeito a direitos e de desumanização de pessoas presas. Para tanto, devem pautar sua prática por uma ética da alteridade - uma a ética dos desconformes - entendida aqui como a abertura ao outro e a disponibilidade de ser interpelada por este. 


\section{REFERÊNCIAS BIBLIOGRÁFICAS}

1. BERGER, Peter. On the obsolescence of the concept of Honor. In: HAUERWAS, Stanley; MACINTYRE; Alasdair. Revisions: changing perspectives in moral philosophy. Norte Dame: Notre Dame University Press, 1983. p. 172-181.

2. BIONDI, Karina. Junto e misturado: imanência e transcendência no PCC. 2009. Dissertação (Mestrado em Antropologia) - Universidade Federal de Santa Catarina, Florianópolis, 2009.

3. BRASIL. Lei $\mathbf{n}^{\circ} \mathbf{7 . 2 1 0}$, de 11 de julho de 1984. Institui a Lei de Execução Penal. Brasília, DF, 1984. Disponível em: http://bit.ly/2N8DyEb. Acesso em: 8 dez. 2019.

4. CARDOSO, Marcus. A dimensão simbólica dos conflitos: moradores de favela e polícia. Anuário Antropológico, Brasília, DF, v. 2012-1, p. 167-190, 2013.

5. CARDOSO, Marcus. Respect, dignity and rights: ethnographic registers about community policing in Rio de Janeiro. Vibrant: Virtual Brazilian Anthropology, Brasília, DF, v. 11, n. 2, p. 46-74, 2014.

6. CONLEY, John; O’BARR, William. Just words: law, language and power. 2nd. ed. Chicago: The University of Chicago Press, 2005.

7. CONVENÇÃO AMERICANA DE DIREITOS HUMANOS. Pacto São José de Costa Rica. Costa Rica, 1969. Disponível em: http://bit.ly/2QzDU8V. Acesso em: 3 jun. 2019.

8. CRUFT, Rowan; LIAO, Matthew; RENZO, Massimo. Philosophical foundations of human rights. Oxford: Oxford University Press, 2014.

9. FIGUEIRA, Luiz Eduardo Vasconcellos. O ritual judiciário do Tribunal do Júri. 2007. Tese (Doutorado em Antropologia) - Universidade Federal Fluminense, Niterói, 2007.

10. FOUCAULT, Michel. Il Faut défendre la société. Paris: Gallimard-Seuil, 1997.

11. FREIRE, Jussara. Agir no regime de desumanização: esboço de um modelo para análise da sociabilidade urbana na cidade do Rio de Janeiro. Dilemas: Revista de Estudos de Conflito e Controle Social, Rio de Janeiro, v. 3, n. 10, p. 119-142, 2010.

12. GEERTZ, Clifford. O saber local: fatos e leis em uma perspectiva comparativa. In: GEETZ, Clifford. O saber local: novos ensaios em antropologia interpretativa. Petrópolis: Vozes, 1998. p. 249-356.

13. GODBOUT, Jacques. Introdução à dádiva. Revista Brasileira de Ciências Sociais, São Paulo, v. 13, n. 38, p. 1-14, 1998.

14. GOFFMAN, Erving. Manicômios, prisões e conventos. São Paulo: Perspectiva, 1974. 
15. HONNETH, Axel. Integrity and disrespect. principles of a conception of morality based on the theory of recognition. Political Theory, Thousand Oaks, v. 20, n. 2, p. 187-201, 1992.

16. HONNETH, Axel. Luta por reconhecimento: a gramática moral dos conflitos sociais. São Paulo: Editora 34, 2003.

17. LEMOS, Carolina Barreto. Puxando pena: sentidos nativos da pena de prisão em cadeias do Distrito Federal. 2017. Tese (Doutorado em Direito) - Universidade de Brasília, Brasília, DF, 2017.

18. LEMOS, Carolina Barreto. Entre direitos, regalias, regras e castigos: sentidos de justiça nas cadeias do Distrito Federal. Revista de Estudos Empíricos em Direito, São Paulo, v. 5, n. 3, p. 136-147, 2018.

19. LIMA, William da Silva. Quatrocentos contra um: uma história do Comando Vermelho. São Paulo: Labortexto Editorial, 2001.

20. MARQUES, A. "Liderança", "proceder" e "igualdade": uma etnografia das relações políticas no Primeiro Comando da Capital. Etnográfica, Lisboa, v. 14, p. 311-335, 2010.

21. MBEMBE, Achille. Crítica da razão negra. Lisboa: Antígona, 2014.

22. MISSE, Michel. Crime, sujeito e sujeição criminal: aspectos de uma contribuição analítica sobre a categoria “bandido". Lua Nova: Revista de Cultura e Política, São Paulo, n. 79, p. 15-38, 2010.

23. OLIVEIRA, Luis Cardoso de. Direito legal e insulto moral: dilemas da cidadania no Brasil, Quebec e EUA. Rio de Janeiro: Garamond, 2011.

24. OLIVEIRA, Luis Cardoso de. Sensibilidade cívica e cidadania no Brasil. Revista Antropolítica, Niterói, n. 44, p. 34-63, 2018.

25. ORGANIZAÇÃO DAS NAÇÕES UNIDAS. O que são direitos humanos? Brasília, DF, [201-?]. Disponível em: http://bit.ly/37POzSG. Acesso em: 3 jun. 2019.

26. RODRIGUES, Nina. As raças humanas e a responsabilidade penal no Brazil. Salvador: Guanabara,1894.

27. SCHWARCZ, Lilia Moritz. Retrato em branco e negro: jornais, escravos e cidadãos em São Paulo no final do século XIX. São Paulo: Companhia das Letras, 1987.

28. SEGATO, Rita Laura. Antropologia e direitos humanos: alteridade e ética no movimento de expansão dos direitos universais. Mana, Rio de Janeiro, v. 2, n. 1, p. 207-236, 2006. 